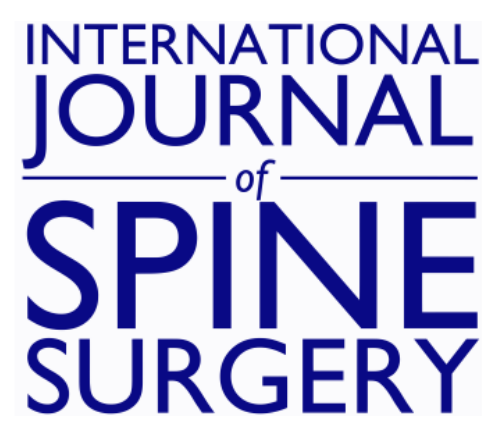

\title{
Trends in Weight and Body Mass Index after Spinal Surgery for Degenerative Disease
}

Donald A. Ross, Sudarshan Iyer and Miner N. Ross

Int J Spine Surg 2021, 15 (4) 834-839

doi: https://doi.org/10.14444/8107

http://ijssurgery.com/content/15/4/834

This information is current as of April 26, 2023.

Email Alerts Receive free email-alerts when new articles cite this article. Sign up at:

http://ijssurgery.com/alerts 


\title{
Trends in Weight and Body Mass Index after Spinal Surgery for Degenerative Disease
}

\author{
DONALD A. ROSS, MD, ${ }^{1,2}$ SUDARSHAN IYER, BSE, ${ }^{2}$ MINER N. ROSS, MPH, MD ${ }^{2}$ \\ ${ }^{I}$ Operative Care Division, Portland Veterans Affairs Medical Center, Oregon Health \& Science University, Portland, Oregon, ${ }^{2}$ Department of Neurological \\ Surgery, Oregon Health \& Science University, Portland, Oregon
}

\begin{abstract}
Background: Currently, $37 \%$ of adults in the United States are obese, and $34 \%$ are overweight. Obesity poses a particularly complex challenge in spinal surgery management, whereby risk of adverse surgical outcomes increases with increased body mass index (BMI). When patients are counseled to reduce weight to levels associated with acceptable surgical risks, patients often respond that their spinal problems prohibit the exercise needed to lose the required weight and counter that surgery will allow for increased activity and thereby facilitate weight loss. A retrospective study of a US Veterans Affairs (USVA) nationwide patient database was undertaken.

Methods: A request was made of the USVA Corporate Data Warehouse for data on all patients undergoing elective spine surgery for degenerative conditions over a 10-year period.

Results: The mean preoperative age of 65667 patients identified was 59 years. The mean preoperative weight was $91.8 \mathrm{~kg}$, and BMI was 29.2. Before surgery, 26772 patients had a BMI of $>30$. After surgery, $12564(46.9 \%)$ lost at least $2.3 \mathrm{~kg}, 9450(35.3 \%)$ gained at least $2.3 \mathrm{~kg}$, and $4758(17.8 \%)$ were unchanged. After surgery, 4853 $(18.1 \%)$ lost at least $11.3 \mathrm{~kg}$ and $1360(5.1 \%)$ lost at least $22.7 \mathrm{~kg}$. At a mean of 1.9 years after index surgery, mean postoperative weight was $92.5 \mathrm{~kg}$, and BMI was 29.4. Of the 65667 patients, $23125(35.2 \%)$ patients lost at least $2.3 \mathrm{~kg}, 27571(42.0 \%)$ gained at least $2.3 \mathrm{~kg}$, and $14971(23.0 \%)$ remained within $2.3 \mathrm{~kg}$ of their preoperative weight.

Conclusion: The study results will aid in counseling patients regarding realistic expectations about weight loss after spinal surgery.

Level of Evidence: 4.

Clinical Relevance: This evidence will allow for realistic patient counseling regarding the likelihood of weight loss after elective spinal surgery.

Other \& Special Categories

Keywords: body mass index, BMI, obesity, spine, spinal, surgery
\end{abstract}

\section{INTRODUCTION}

The United States is part of a world-wide obesity epidemic, with $37 \%$ of adults classified as obese and $34 \%$ as overweight. ${ }^{1}$ If current trends continue unabated, half of the United States will be obese by 2030. ${ }^{1}$ Obesity results in direct comorbidities, such as diabetes mellitus, heart disease, stroke, cancer, reduced ability to fight infection, and poor sleep, among other conditions. ${ }^{1}$ In addition, obesity increases the risks of elective surgery, including spinal surgery. ${ }^{2-5}$

When patients are counseled that they should not undergo elective spinal surgery until they have reduced their weight to levels associated with acceptable surgical risks, patients often respond that their spinal problems prohibit the exercise needed to lose weight. Instead, they propose that spinal surgery to relieve their symptoms will then allow them to return to their former, active lifestyle and, thereby, lose the weight that they have gained due to inactivity. To test if this goal is actually achieved after spinal surgery, a retrospective study was conducted using a nationwide database of US Veterans Affairs patients.

\section{METHODS}

\section{Study Population and Data Collection}

A request was made of the US Veterans Affairs Corporate Data Warehouse for access to the National Veterans Affairs Database in Austin, Texas, using the Veterans Affairs Informatics and Computing Infrastructure Data Access Research Tracker. A request was made for data on all 

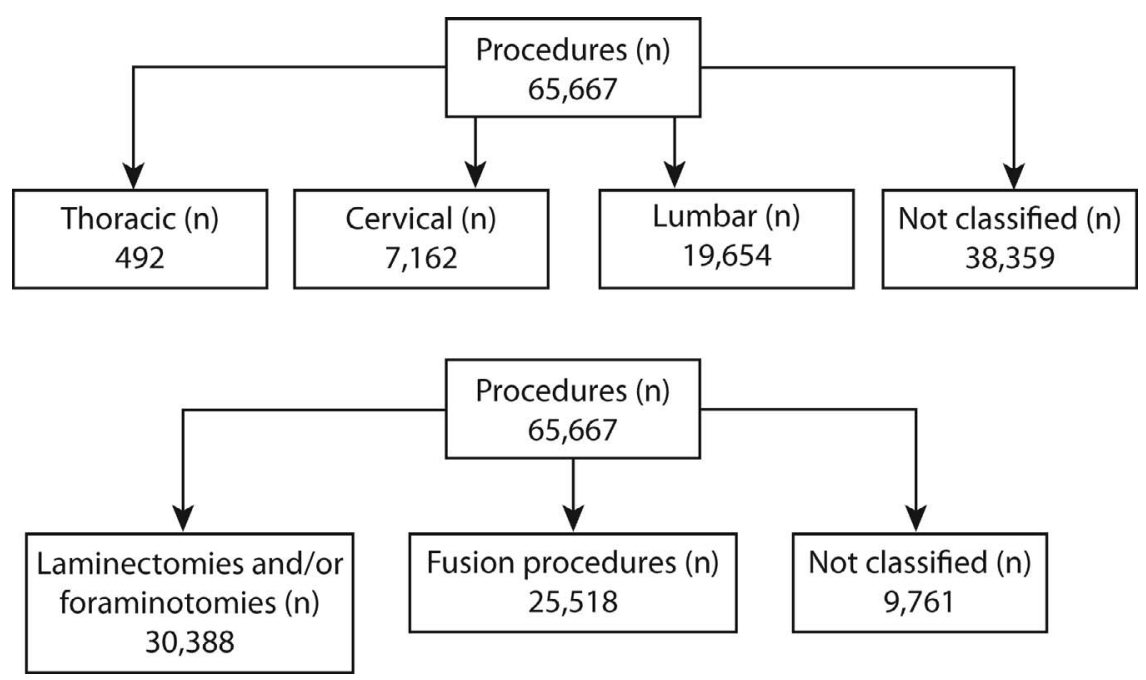

Veterans Affairs patients undergoing elective spine surgery for degenerative spine conditions over a 10year period. This included laminectomies (Current Procedural Terminology codes 63005, 63017, 63042, 63045, and 63047), discectomies (63030), foraminotomies (63045, 63047, and 63048), anterior cervical discectomy and fusions (63075, 22551, and 22845), cervical arthroplasty (22856), cervical laminoplasty (63050), posterior cervical fusions (22590, 22595, 22600, and 22614), anterior lumbar fusions (22558, 22585,22845 , and 22851), and posterior lumbar fusions (22612, 22630, 22840, 22842, and 22843). Surgeries for trauma, infection, or neoplasms were excluded.

The data requested were patient age, date of surgery, weight, height, hemoglobin A1c, and body mass index (BMI) for patients in the 3 months before surgery and at least 1 year after surgery and any surgery complications.

\section{Statistical Analysis}

Descriptive statistics were used to summarize demographic and clinical characteristics in patients having spine surgery. Data were received as structured query language and transferred to Microsoft Excel (Microsoft Inc, Redmond, Washington) for analysis. Regression analysis was undertaken using SAS 9.2 (SAS Inc, Cary, North Carolina).

\section{Human Investigation Approvals}

This study was approved by and compliant with the institutional review board with a waiver of patient consent.
Figure 1. Procedure breakdown of 65667 patients who underwent elective spine surgery.

\section{RESULTS Clinical Data and Demographics}

The structured query language database file contained 430000 lines of data. After flattening into an Excel spreadsheet, we undertook removal of redundant entries with multiple current procedural terminology codes for the same procedure and procedures not meeting criteria. After this refinement, there were 191320 unique procedures. We then removed patients for whom pre- and postoperative weight and height were not available, excluded any entries with weights $>226.8 \mathrm{~kg}$ or $<34.0 \mathrm{~kg}$, and excluded any entries with heights $>2.1 \mathrm{~m}$ or $<1.5 \mathrm{~m}$, leaving 65667 unique procedures for analysis.

Of the 65667 procedures, 7162 were cervical, 492 were thoracic, and 19654 were lumbar; 38359 procedures could not be classified. Additionally, 30388 procedures were laminectomies and/or foraminotomies, 25518 procedures involved a fusion procedure, and 9761 procedures could not be further classified (Figure 1).

The mean preoperative patient age was 59 years (standard deviation $[\mathrm{SD}] \pm 12$ years). Patient racial distribution was $74.2 \%$ White, $16.7 \%$ Black, $0.4 \%$ Asian, $1.1 \%$ Native American or Alaska Native, $1.1 \%$ Native Hawaiian or Pacific Islander, and $5.5 \%$ with no designation $(4.2 \%$ were noted ethnically as Hispanic or Latino). Patients were 93.9\% male. Among all patients, 17473 had a hemoglobin Alc checked within 3 months before surgery. Mean hemoglobin A1c in this group was $6.54(\mathrm{SD} \pm 1.30)$. Mean preoperative patient weight was $91.8 \mathrm{~kg}(\mathrm{SD} \pm 20 \mathrm{~kg})$. Mean preoperative BMI 
Table 1. Weight data for 65667 patients who underwent elective spine surgery at 1.9 years after index surgery.

\begin{tabular}{lc}
\hline Parameter & Mean (SD) \\
\hline Age, y & $59(5.0)$ \\
Preoperative weight, $\mathrm{kg}$ & $91.8(16.9)$ \\
Preoperative BMI, kg/m & $29.2(5.0)$ \\
Postoperative weight, kg & $92.5(12.5)$ \\
Postoperative BMI, $\mathrm{kg} / \mathrm{m}^{2}$ & $29.4(5.1)$ \\
Weight gain, $\mathrm{kg}$ & $0.7(11.0)$ \\
BMI increase, $\mathrm{kg} / \mathrm{m}^{2}$ & 0.2 \\
\hline
\end{tabular}

Abbreviation: BMI, body mass index.

was $29.2 \mathrm{~kg} / \mathrm{m}^{2}(\mathrm{SD} \pm 5.0)$. At a mean of 1.9 years (range 1 to 16 years) after the index surgery, mean postoperative weight was $92.5 \mathrm{~kg}(\mathrm{SD} \pm 17.2 \mathrm{~kg})$ and $\mathrm{BMI}$ was $29.4 \mathrm{~kg} / \mathrm{m}^{2}(\mathrm{SD} \pm 5.1)$.

By two-tailed $t$ tests, both the change in weight $(T=-16.6, P<.001)$ and the BMI $(T=-17.4, P<$ $.001)$ were significant. Of the 65667 patients, $23125(35.2 \%)$ lost at least $2.3 \mathrm{~kg}, 27571$ $(42.0 \%)$ gained at least $2.3 \mathrm{~kg}$, and 14971 $(23.0 \%)$ remained within $2.3 \mathrm{~kg}$ of their preoperative weight (Table 1).

We found that 26772 patients $(40.8 \%)$ were obese (BMI $>30)$ before surgery. The mean age, sex distribution, and racial/ethnic distribution of these patients were similar to the entire cohort. However, $33.5 \%$ of these patients were tested for hemoglobin A1c level before surgery, whereas $26.7 \%$ of the entire data set were so tested. Mean weight loss among these 26772 patients was $2.2 \mathrm{~kg}$. Of those patients, $12564(46.9 \%)$ lost at least 2.3 $\mathrm{kg}$ after surgery, 9450 patients $(35.3 \%)$ gained at least $2.3 \mathrm{~kg}$ after surgery, and $4758(17.8 \%)$ remained within $2.3 \mathrm{~kg}$ of their preoperative weight. Of the 26772 obese patients, 4853 $(18.1 \%)$ lost at least $11.3 \mathrm{~kg}$, and $2650(9.9 \%)$ gained at least $11.3 \mathrm{~kg}$ after surgery, while 1360 $(5.1 \%)$ lost at least $22.7 \mathrm{~kg}$ and $441(1.6 \%)$ gained at least $22.7 \mathrm{~kg}$ after surgery (Table 2).

Linear regression analysis was used to evaluate predictors of weight and/or BMI change in our data set. We found that age at surgery was significantly predictive of a decrease in weight (coefficient -0.442 , $P<.0001$ ) as well as BMI (coefficient $-0.062, P<$ $.0001)$ postoperatively. Conversely, diabetes or suspected diabetes, inferred by the presence of preoperative hemoglobin A1c testing, predicted a postoperative increase in weight (coefficient $0.773, P$ $=.0001$ ) as well as BMI (coefficient 0.140, $P<$ $.0001)$. We included the preoperative weight and BMI in our models of weight and BMI change, respectively, suspecting that obese patients may be
Table 2. Weight data for 26772 obese $(\mathrm{BMI}>30)$ patients who underwent elective spine surgery.

\begin{tabular}{lc}
\hline Parameter & Value \\
\hline Mean weight loss, $\mathrm{kg}$, mean $\pm \mathrm{SD}$ & $2.2 \pm 12.1$ \\
Patients within $2.3 \mathrm{~kg}$ of preoperative weight, $n(\%)$ & $4758(7.8)$ \\
Patients who lost, $n(\%)$ & \\
$>2.3 \mathrm{~kg}$ & $12564(46.9)$ \\
$>11.3 \mathrm{~kg}$ & $4853(18.1)$ \\
$>22.7 \mathrm{~kg}$ & $1360(5.1)$ \\
Patients who gained, $n(\%)$ & \\
$>2.3 \mathrm{~kg}$ & $9450(35.3)$ \\
$>11.3 \mathrm{~kg}$ & $2650(9.9)$ \\
$>22.7 \mathrm{~kg}$ & $441(1.6)$ \\
\hline
\end{tabular}

Abbreviation: BMI, body mass index.

more likely to lose weight. This bears out, as postoperative weight change was predicted by preoperative weight (coefficient $-0.191, P<$ .0001 ), and postoperative BMI change was predicted by preoperative BMI (coefficient $-0.210, P<$ .0001).

We also looked at just the patients who underwent clearly documented lumbar surgery, as some feel that lumbar surgery may have a greater effect on mobility than surgery on other spine segments. The age, sex, and racial/ethnic distribution of these patients were similar to the entire data set. The mean weight and BMI before surgery in this group were $92.5 \mathrm{~kg}$ and $29 \pm 4.9 \mathrm{~kg} / \mathrm{m}^{2}$, respectively. The mean weight and BMI after surgery were $93.9 \mathrm{~kg}$ and $30 \pm 5.0 \mathrm{~kg} / \mathrm{m}^{2}$, respectively.

\section{DISCUSSION}

Our data appear to show that in a large group of 65667 patients undergoing surgery for degenerative spine conditions, overall weight and BMI increased slightly $\left(0.7 \mathrm{~kg}, 0.2 \mathrm{~kg} / \mathrm{m}^{2}\right)$ and statistically significantly at 1.9 years after the index surgery, but this change may not be clinically relevant (see discussion below). When looking at patients with a BMI of $>30$ before the index surgery, $46.9 \%$ did lose at least $2.3 \mathrm{~kg}$ after surgery, but $35.3 \%$ gained at least $2.3 \mathrm{~kg}$ after surgery. In a smaller group from these same patients, $18.1 \%$ lost at least $11.3 \mathrm{~kg}$, and only $5.1 \%$ lost at least $22.7 \mathrm{~kg}$ after surgery. Therefore, although the chances of major weight loss after spine surgery are not high, they are not negligible. Predictors of postoperative weight loss in our data included increasing age at surgery and higher preoperative weight and/or BMI, but the coefficients are small and not suggestive of a strong clinical effect of surgery. It is also possible that the 
trajectory of weight gain before the surgery may have been slowed by surgery and that stability may indicate some benefit of intervention, but our data set could not answer this question.

Other reports have addressed this issue. A recent report from the Kaiser National Spine Registry included 7303 patients who had undergone lumbar fusion surgery. ${ }^{6}$ The mean age was 61.7 years. At the time of surgery, $4456(61 \%)$ had a BMI of $<30$, $2519(34.5 \%)$ had a BMI between 30 and 39, and $232(3.2 \%)$ had a BMI of $>40$. Weight loss greater than or equal to $5 \%$ at 1 year after surgery occurred in $11.1 \%, 16.6 \%$, and $21.1 \%$, respectively. In the obese group, average weight loss was $0.9 \mathrm{~kg}$, and in the severely obese group, average weight loss was $3.2 \mathrm{~kg}$. The authors found these results encouraging because they are similar to those reported with popular diets, but studies have not found similar losses to be clinically relevant. ${ }^{7}$ No results were available beyond 1 year.

When looking at patient-reported outcomes after lumbar fusion surgery, one small study has suggested no benefit to successful lumbar fusion in terms of weight reduction. ${ }^{8}$ In this study, 56 patients (mean age 55.6 years) with a BMI of $>30$ undergoing a single-level lumbar interbody fusion were included if they achieved a minimum clinically important difference in Oswestry Disability Index of 15 points at a minimum of 1 year of follow-up. The mean change in BMI was $+0.15 \pm 2.1 \mathrm{~kg} / \mathrm{m}^{2}$. The conclusion was that even after successful lumbar fusion surgery, obese patients had no significant change in BMI after surgery.

In a Swedish Spine Register report, 538 obese patients (mean age 66 years) undergoing surgery for lumbar spinal stenosis were noted to have lost $1.9 \mathrm{~kg}$ 1 year after surgery and $2.0 \mathrm{~kg} 2$ years after surgery. ${ }^{7}$ Only $8 \%$ of patients reported a clinically important weight loss of greater than or equal to $10 \%$ of body weight. Changes in weight were unrelated to patient-reported outcome measures of EQ-5D, Oswestry Disability Index, and visual analog pain scales for back and leg pain. While the weight changes were statistically significant due to the sample size, the authors admit that they are not likely clinically relevant and could have been due to natural aging.

A literature review was conducted in 2010 of publications between 1970 and 2010 discussing weight changes after spinal surgery. ${ }^{9}$ Two articles met criteria, both of which are discussed below. ${ }^{10,11}$
In one reviewed study, a group of 63 obese and morbidly obese patients (average age 53 years) undergoing lumbar fusion, including multilevel procedures, was followed for 14 to 37 months; a postoperative weight was available in 58 patients. ${ }^{11}$ Twenty-four gained weight, 23 lost weight, and 11 were unchanged after surgery. Improvements in back pain and Oswestry scores did not correlate with weight loss. The authors concluded that spinal surgery did not result in weight loss. In a second group of 63 patients (mean age 53.4 years) followed for a mean of 34.4 months after lumbar decompression, a weight gain of $2.48 \mathrm{~kg}$ and a BMI increase of $0.83 \mathrm{~kg} / \mathrm{m}^{2}$ were reported; $59 \%$ remained within $5 \%$ of their preoperative body weight. ${ }^{10}$ No correlation was found with outcome measures, including the Zurich Claudication Questionnaire, which were overall improved. The authors concluded that even substantial improvements in symptoms do not lead to weight loss. The authors of the literature review found no evidence that weight loss was likely after lumbar spine surgery.

Use of accelerometers after spine surgery suggests that there may not be a correlation between improvements in subjective clinical outcome scores and changes in physical activity. ${ }^{12}$ In this study, 30 patients were prospectively given a Fitbit accelerometer (Fitbit Inc, San Francisco, California) starting 7 days before the index lumbar spine decompression or fusion surgery. Although there were increases in mean steps per day $(58.2 \%)$ and distance traveled per day $(63 \%)$ at 3 months after surgery, there was no significant correlation between these parameters and patient-reported outcome measures. Therefore, improvements in well-being may not translate into increased physical activity for some patients.

Even if successful spinal surgery can result in increased physical activity, patients may be overly optimistic that an incremental increase in their ability to exercise will result in weight loss. Recent studies have cast doubt on the role of exercise alone in weight reduction, although it may be helpful in maintaining a healthy weight. ${ }^{1,13-16}$ In part, this understanding has come from sophisticated doublelabeled water methods to determine daily energy expenditure, which have shown only small differences between sedentary Americans and indigenous populations leading very active lives. ${ }^{14,15}$ Physical activity may be responsible for only one third of total daily energy expenditure, while the body's 
basal metabolism makes up the other two thirds. ${ }^{1}$ According to Lean et al, ${ }^{13}$ "although exercise has a small weight loss benefit when combined with an energy restricted food plan, neither aerobic nor resistance exercise in typical amounts are effective as a sole strategy."

There is some evidence that even small amounts of weight loss may benefit patients with type 2 diabetes. ${ }^{17,18}$ In a group of 119 patients with type 2 diabetes mellitus who underwent successful lumbar decompression and/or fusion surgery, hemoglobin A1c went from 7.08 before surgery to 6.59 two years after surgery. ${ }^{18}$ This reduction correlated with patient-reported outcome measures, including Oswestry Disability Index and Japanese Orthopedic Association Scores, and was attributed to increased physical activity. There was also a reduction in BMI 2 years after surgery, from an average of 25.1 before surgery to 23.78 after surgery. This population was not obese before surgery and may not be analogous to an American population.

\section{Limitations}

Study limitations include those inherent to retrospective review. The patients were operated on in many hospitals by many different surgeons and underwent an array of cervical, thoracic, and lumbar surgeries. We were not able, with the coding provided in this database, to discern the exact spinal location and nature of many of the cases, which fell into nonspecific categories (many codes referred to undefined levels, used "thoracic or lumbar" or other nonspecific terms, etc). No patient-reported outcome data are available for these patients, so we do not know if the surgeries achieved their intended goals. We do not know if another medical condition, such as subsequent cancer or steroid use, affected the weights of postoperative patients. Our patients were slightly older than some of the other studies cited above, but were younger than others. Furthermore, veterans are overwhelmingly male patients. We do not know how weight assessments were conducted; most patients in physicians' offices are weighed fully clothed and with items in their pockets. Therefore, small weight variations may be due to a cell phone in a pocket rather than a true change in body mass. Height and/or weight may have been self-reported rather than actually measured.

Alternatively, this study involves a very large group of patients (orders of magnitude larger than prior studies) undergoing surgeries for degenerative spinal conditions in real-world settings. The patients represent many racial and ethnic groups and ages. The weights were recorded at clinic visits and are not dependent on self-reporting. Other studies cited above included patient-reported outcome data but in much smaller groups of patients and only in lumbar spine surgeries. Consequently, the sizable cohort in our study adds more data and provides credibility to the claims made in these smaller studies.

\section{CONCLUSION}

In summary, our study found that weight loss was no likelier than weight gain after spinal surgery, thus contradicting the expectations of many surgical patients. The general population may not benefit from clinically relevant weight loss after spinal surgery. Moving forward, our results will provide useful information when counseling patients about realistic expectations of weight loss after spinal surgery.

\section{REFERENCES}

1. Roberts SB, Das SK. The messy truth about weight loss. Sci Am. 2017;316(6):36-41.

2. Higgins DM, Mallory GW, Planchard RF, et al. Understanding the impact of obesity on short-term outcomes and in-hospital costs after instrumented spinal fusion. Neurosurgery. 2016;78(1):127-132.

3. McClendon J, Smith TR, Thompson SE, et al. The impact of body mass index on hospital stay and complications after spinal fusion. Neurosurgery. 2014;74(1):42-50.

4. Seicean A, Alan N, Seicean S, et al. Impact of increased body mass index on outcomes of elective spinal surgery. Spine (Phila Pa 1976). 2014;39(18):1520-1530.

5. Wathen C, Kshettry VR, Krishnaney A, et al. The association between operating room personnel and turnover with surgical site infection in more than 12000 neurosurgical cases. Neurosurgery. 2016;79(6):889-894.

6. Akins PT, Inacio MCS, Bernbeck JA, et al. Do obese and extremely obese patients lose weight after lumbar spine fusions? Analysis of a cohort of 7303 patients from the Kaiser National Spine Registry. Spine (Phila Pa 1976). 2018;43(1):22-27.

7. Knutsson B, Michaëlsson K, Sandén B. Obese patients report modest weight loss after surgery for lumbar spinal stenosis. Spine (Phila Pa 1976). 2014;39(20):1725-1730.

8. Joseph JR, Farooqui Z, Smith BW, et al. Does clinical improvement of symptomatic degenerative lumbar disease impact obesity? J Neurosurg Spine. 2017;26(6):705-708.

9. Anderson P, Dettori J, Hermsmeyer J. Does lumbar decompression in overweight patients assist in postoperative weight loss? Evid Based Spine Care J. 2010;1(2):34-38.

10. Garcia RM, Messerschmitt PJ, Furey CG, Bohlman HH, Cassinelli EH. Weight loss in overweight and obese patients 
following successful lumbar decompression. J Bone Joint Surg Am. 2008;90(4):742-747.

11. Vaidya R, Carp J, Bartol S, Ouellette N, Lee S, Sethi A. Lumbar spine fusion in obese and morbidly obese patients. Spine (Phila Pa 1976). 2009;34(5):495-500.

12. Mobbs RJ, Phan K, Maharaj M, Rao PJ. Physical activity measured with accelerometer and self-rated disability in lumbar spine surgery: a prospective study. Global Spine J. 2015;6(5):459-464.

13. Lean MEJ, Astrup A, Roberts SB. Making progress on the global crisis of obesity and weight management. $B M J$. 2018:k2538. doi:10.1136/bmj.k2538

14. Pontzer H. The crown joules: energetics, ecology, and evolution in humans and other primates. Evol Anthropol. 2017;26(1):12-24.

15. Pontzer H. The exercise paradox. Sci Am. 2017;316(2):26-31.

16. Wong K. The new origins of technology. Sci Am. 2017;316(5):28-35.

17. Kim H-J, Lee K-W, Cho H-G, et al. Indirect effects of decompression surgery on glycemic homeostasis in patients with type 2 diabetes mellitus and lumbar spinal stenosis. Spine J. 2015;15(1):25-33.

18. Kim K-T, Cho D-C, Sung J-K, Kim CH, Kang H, Kim DH. Changes in $\mathrm{HbA}_{1 \mathrm{c}}$ levels and body mass index after successful decompression surgery in patients with type 2 diabetes mellitus and lumbar spinal stenosis: results of a 2-year follow-up study. Spine J. 2017;17(2):203-210.

Disclosures and COI: The authors have no personal, financial, or institutional interest in any of the drugs, materials, or devices described in this article. No authors had any conflicts of interest or disclosures that have directly or indirectly influenced this study.

Corresponding Author: Donald A. Ross, MD, Department of Neurological Surgery, 3303 S Bond Ave, Mail Code CH8N, Oregon Health \& Science University, Portland, OR 97239. Phone: (503) 494-4314; Email: rossdo@ohsu.edu.

Published 19 August 2021

This manuscript is generously published free of charge by ISASS, the International Society for the Advancement of Spine Surgery. Copyright (c) 2021 ISASS. To see more or order reprints or permissions, see http://ijssurgery.com. 